\title{
Sperm Quality and Histology of the Testis and Epididymis in Chemical Castrated Male Cats with Intra-testicular Injection of Sodium Chloride Solution
}

\author{
Marissa Divia Dayanti ${ }^{1}$ I Ketut Berata ${ }^{2}$, and I Ketut Puja ${ }^{3 *}$ \\ ${ }^{I}$ Faculty of Veterinary Medicine, Udayana University, Bali, Indonesia \\ ${ }^{2}$ Veterinary Pathology, Faculty of Veterinary Medicine, Udayana University, Bali, Indonesia \\ ${ }^{3}$ Veterinary Genetics and Reproduction Technology Laboratory, Faculty of Veterinary Medicine, Udayana University, Bali, Indonesia \\ *Corresponding author's Email: asubali@unud.ac.id; (DORCiD: 0000-0002-3171-6904
}

\begin{abstract}
The high population of feral cats in Bali, Indonesia, could be a problem associated with cat welfare and the risk of zoonotic diseases. Gonadectomy or male castration is an option for population control; however, there would be more economical ways to reach this goal. Sterilization using chemicals is an alternative to the surgical method of castration as it is reasonably priced, activated in a short time, and does not affect animal activity after the chemical administration. The present study aimed to evaluate intratesticular injection of Sodium chloride as an agent of chemosterilants in male cats. In the current study, 16 healthy male cats aged nearly one year old were randomly selected. The male cats were allocated into four groups containing four cats in each. Group 1 (control) received bilateral intratesticular injection with $0.25 \mathrm{~mL}$ normal saline solution containing $2 \%$ Lidocaine. The cats in groups 2 , 3 , and 4 received bilateral intratesticular injection of $0.25 \mathrm{~mL}$ Sodium chloride solution containing $2 \%$ Lidocaine with a concentration of $15 \%, 20 \%$, and $25 \%$, respectively. At the end of the study (after 30 days of injection), the cats were castrated and their testes were removed for sperm quality and histopathological evaluation. The results of the present study indicated that intratesticular injection of Sodium chloride significantly decreased the motility and viability rates, and increased the abnormalities of the sperms. Histopathological studies revealed marked depletion of spermatozoa in the testes and seminiferous tubular degeneration, seminiferous tubular atrophy, and epithelial cell vacuolation. In conclusion, the injection of $20-25 \%$ solution of Sodium chloride in testes had the potential as a chemosterilant for chemical sterilization in cats.
\end{abstract}

Keywords: Cat, Histopathology, Sodium chloride, Sperm quality

\section{INTRODUCTION}

The domestic cat (Felis catus) population is increasing worldwide leading to increased contact with humans and wildlife, which is a global problem associated with risks to public health (Flockhart and Coe, 2018). This contact is highly potential for spreading zoonotic disease (Kennedy et al., 2020). Moreover, the increasing number of cats can be a problem in animal welfare (Leoci et al., 2014).

Recently, several countries have implemented a Trap-Neuter-Release (TNR) program to reduce cat populations without harmful effects on their welfare (Mitsui et al., 2020). The TNR method was used most frequently on unsocialized cats. Until recently, male gonadectomy or castration is the most commonly accepted method for controlling the population of cats and is considered a standard gold means of sterilizing male animals (Ibrahim et al., 2016). As it requires anesthesia, sterile medical equipment, a trained veterinarian, and postoperative care and management, an affordable alternative way for neutering cats would be helpful for people all around the world. In this regard, researchers are interested in developing chemical sterilization methods as an alternative to surgical methods to overcome the mentioned obstacles.

The chemical sterilization method is an alternative to surgical contraception by injecting chemicals into the testes, epididymis, or vas deferens, causing testicular degeneration and damaging the spermatogenesis process (Rafatmah et al., 2019). Sterilization using chemicals is inexpensive, affects in a short time, and does not impact animal activity after chemical administration (Cavalieri, 2017; Hassan and Fromsa, 2017). Several agents of chemosterilants (including Calcium chloride, Lactic acid, Sodium chloride, Chlorhexidine, Formalin, Zinc tannate, Zinc gluconate, Glycerol, Glucose, Ethanol, and silver nitrate) have been successfully tried on some animal species, such as donkeys (Ibrahim et al., 2016), dogs (Leoci et al., 2014; Rafatmah et al., 2019), and rats (Kwak et al., 2010) as a method for sterilization. Among the commonly used chemicals, Sodium chloride or table salt is a readily accessible and inexpensive ingredient. 
The use of Sodium chloride solution injected directly into the testes appeared to be a promising method of castration. Sodium chloride injection is inexpensive, efficacious, and minimally invasive. In mice injected with a $20 \%$ concentration of Sodium chloride solution, it was encouraging as a substitute for castration with surgical methods, and this injection led to no impact on skin, necrosis development, and abscesses (Emir et al., 2008). In dogs, direct injection of $20 \%$ Sodium chloride into the testes was found an effective method to use (Canpolat et al., 2016). To date, there are no data regarding the evaluation of sperm quality and the histology of the testis and epididymis due to direct injection of sodium chloride solution.

The present research aimed to evaluate intratesticular injection of different concentrations of sodium chloride in male cats based on changes in sperm quality and histopathological changes in testis and epididymis.

\section{MATERIALS AND METHODS}

\section{Ethical approval}

The current study was conducted following the principles and guidelines of animal care. All procedures of the study have been approved by the Animal Ethics Committee, Faculty of Veterinary Medicine Udayana University, Indonesia (Certificate No.103/UN14.2.9/PT.01.04/2020).

\section{Animals and experimental protocol}

A total of 16 healthy male cats aged nearly one year old who had previously mating experience with queens and with no visible abnormalities in their testicles were used in the present study. All animals were clinically examined before the experiment. The cats were divided into four groups, containing four cats in each. Group 1 (control) received a bilateral intratesticular injection with $0.25 \mathrm{~mL}$ normal saline solution containing $2 \%$ Lidocaine. The cats of group 2 , group 3, and group 4 received a bilateral intratesticular injection of $0.25 \mathrm{~mL}$ sodium chloride/ $\mathrm{NaCl}\left(\mathrm{EMSURE}^{\circledR}\right.$; Merck, Germany) solution, respectively, at concentrations of $15 \%, 20 \%$, and $25 \%$ which contained $2 \%$ lidocaine. The amount of $\mathrm{NaCl}$ solution administered was according to the studies of Jana and Samanta (2011) and Ijaz et al. (2019).

The hair around the scrotum was shaved and disinfected with a povidone-iodine solution. Then, samples were injected single intratesticular with needle 27 -gauge $1 / 2$ inch directed into the Caudo-ventral testis approximately $0.5 \mathrm{~cm}$ from the cauda epididymis towards the cranial aspect of the testis.

\section{Sample collection}

Thirty days following intratesticular injection, the testes together with epididymis were excised by castration (Toyonaga and Tsutsui, 2012). After the samples were collected, these organs were washed with saline solution. The complete testes with epididymis were placed in a sterile plastic container in $0.9 \% \mathrm{NaCl}$ solution at $37^{\circ} \mathrm{C}$ and transported to the laboratory for further analysis. The epididymis was isolated, and sperm was obtained by making an incision in the epididymal duct (de Sousa Barbosa et al., 2019). The sperm was flushed with a five $\mathrm{mL}$ saline solution. The liquid was collected in a petri dish. The testicles and epididymis were fixed in $10 \%$ of normal buffer formaldehyde solution for histological studies.

\section{Sperm evaluation}

To evaluate sperm progressive motility, an aliquot of the sperm sample was placed on a glass object covered with a warmed coverslip. The glass object was prewarmed at $38^{\circ} \mathrm{C}$ before being used. Motility was observed under a light microscope at 200×. Motility was estimated as the percentage of motile spermatozoa (0-100\%, Macente et al., 2018).

To assess the number of live-dead sperm, the eosin-nigrosine stain technique was used (Belhan and Gülyüz, 2018). One drop of the sperm was placed on the glass object, and $50 \mu \mathrm{L}$ of warm eosin-nigrosine was added, and then mixed for 15 seconds. Then diluted semen was prepared by the smear technique (Pintus et al., 2021). For each sample, 100 cells were assessed using a light microscope $(100 \times)$. Dead spermatozoa stained red, whereas live spermatozoa were marked with the absence of color. The percentage of abnormal sperm was evaluated using eosin-nigrosine staining. The morphology of the abnormalities that occurred in the spermatozoa was evaluated under a light microscope with a magnification of 1000x. For each sample, 100 cells were assessed. Morphological abnormalities were classified as head abnormalities, tail abnormalities and, midpiece defects (Macente et al., 2018).

\section{Histopathological examination}

The testes and epididymis from each cat were fixed in $10 \%$ neutral buffered formalin solution, and after the routine histopathological processing, tissue samples were embedded in paraffin wax. Tissue sections with five $\mu$ thickness were cut and mounted afterward on the glass slides. Then, they were stained with Hematoxylin-eosin, and examined under light microscopy at $400 \times$ magnification. The structures of the seminiferous tubules and interstitial spaces in the testis and epididymis were examined (Abshenas et al., 2013). 


\section{Statistical analyses}

The results were analyzed using a one-way analysis of variance (ANOVA) followed by the Least Significant Difference (LSD) test to identify the significant differences (Heath, 1995). The level of significance was set at $\mathrm{p}<0.05$. The statistical analysis of all data was made using the SPSS software package program (Version 21). The data were tested for normality using Kolmogorov-Smirnov and Shapiro-Wilk test. The results are presented as the mean \pm standard error of the mean (SEM). Data for histological changes of the testes and epididymis were analyzed descriptively.

\section{RESULTS}

\section{Clinical observation}

Based on clinical observation, all of the cats were appearing healthy. The observed testes were normal and without inflammation. The cats' behavior showed no changes, and appetite, heart auscultation, and body temperature were normal. There were no deaths during the study. In the control group and group 2, some cats showed spraying behavior.

\section{Sperm quality}

The percentages of progressive motility, viability, and abnormality epididymal sperm at day thirteenth post intratesticular injection of Sodium chloride in each concentration are shown in Table 1. The means of sperm motility in groups $1,2,3$, and 4 were $58.75 \pm 8.84 \%, 31.25 \pm 5.91 \%, 10.50 \pm 3.41 \%$, and $8.25 \pm 3.40 \%$, respectively, 30 days after the intratesticular injection of Sodium chloride. The means percent of sperm viability at day 30 post-injection in each concentration were $74.75 \pm 5.91 ; 72.25 \pm 9.35,55.00 \pm 6.48$, and $36.50 \pm 8.06$, respectively. The abnormalities of sperm were $15.75 \pm 2.98 \%, 23.35 \pm 2.50 \%, 36.50 \pm 8.06 \%$ and $38.25 \pm 9.03 \%$, respectively. Interestingly, the motility started to exhibit a significant decrease at the dose of $15 \%$ Sodium chloride, however, viability exhibited a significant decrease at the dose of $20 \%$ Sodium chloride. Moreover, abnormality started a significant increase at the dose of $20 \%$ Sodium chloride. The results showed that administration of sodium chloride significantly decreased the sperm progressive motility, viability, and abnormality across all groups $(\mathrm{p}<0.05)$.

The decrease in sperm motility with the injection of $20 \%$ and $25 \%$ Sodium chloride was more rapid, compared to the control group and injection of $15 \%$ of sodium chloride $(\mathrm{p}<0.05)$. Injection of sodium chloride has an impact on viability and abnormalities at doses of $20 \%$ and $25 \%$. The sperm abnormalities found in the present study included a doubleheader with a coiled tail, bent neck, double tail, macrocephalic, microcephalic, and elongated head (Figure 1).

\section{Histological study}

The histological examination of the testes from Sodium chloride-treated groups was comparable to that of the control group. Generally, there were histological changes observed in the testes of the Sodium chloride-treated groups. The results of the present study regarding the histopathology of the testes in the study Group 1 (the control group) are shown in Figure 2 ( $a$ and b). Microscopic examination of testicles from group 1 indicated normal parenchyma testis, the spermatogenesis showed a normal stage of spermatogenesis, and their tubules were normal with spermatozoa visible in the lumen. Histopathology of the testes in the study groups 2, 3, and 4 showed that $\mathrm{NaCl}$ altered the tissues of the testis compared to that of the control group. The obtained results from group 1 (Figures $2 \mathrm{c}$ and $\mathrm{d}$ ) showed that the seminiferous tubules slightly shrank, the lumen was not filled with spermatids, and the number of germ cells decreased with vacuolated small cells. In the study group 3 (Figures $3 a$ and b), no sperm was observed in the lumen of the tubule. The parenchyma had a small size and wider intertubular space, compared to the control group, and atrophy was observed. In the cats receiving an intratesticular injection with $25 \%$ Sodium chloride (Group 4), focal moderate seminiferous tubular degeneration increases intertubular spaces and a dilated lumen due to a limited amount of germ cells were observed (Figures $3 \mathrm{c}$ and d). Histopathological studies on sections of the epididymis of the Control group showed that the lumen of the epididymis duct filled with spermatozoa (Figure 4a). The intratesticular injection treatment with $15 \%$ Sodium chloride showed that the epididymal duct was filled with few spermatozoa or there was also an empty duct (Figure 4b). In the groups that were treated with $15 \%$ (Group 2), and $20 \%$ Sodium chloride (Group 3), the ducts were filled with spermatozoa. However, in the group study treated with $20 \%$ Sodium chloride, epithelial vacuolation was observed (Figure 4c). In the study group treated with $25 \%$ Sodium chloride, there was a significant depletion of spermatozoa in the epididymis.

Table 1. Evaluation of sperm quality at the day 30 post intratesticular injection of sodium chloride in male cats

\begin{tabular}{lccc}
\hline Group & Progressive motility (\%) & Viability (\%) & Abnormality (\%) \\
\hline Group 1 (Control) & $58.75 \pm 8.84^{\mathrm{a}}$ & $74.75 \pm 5.91^{\mathrm{a}}$ & $15.75 \pm 2.98^{\mathrm{a}}$ \\
Group 2 (15\% Sodium chloride) & $31.25 \pm 5.91^{\mathrm{b}}$ & $72.25 \pm 9,35^{\mathrm{a}}$ & $23.35 \pm 2.50^{\mathrm{a}}$ \\
Group 3 (20\% Sodium chloride) & $10.50 \pm 3.41^{\mathrm{c}}$ & $55.00 \pm 6.48^{\mathrm{b}}$ & $36.50 \pm 8.06^{\mathrm{b}}$ \\
Group 4 (25\% Sodium chloride) & $8.25 \pm 3.40^{\mathrm{c}}$ & $36.50 \pm 8.06^{\mathrm{c}}$ & $38.25 \pm 9.03^{\mathrm{b}}$ \\
\hline
\end{tabular}

Data are shown as mean \pm S.D, $n: 4$, Superscript with different letters in one column showed significantly different results with $95 \%$ significance $(\mathrm{p}<$ $0.05)$. 


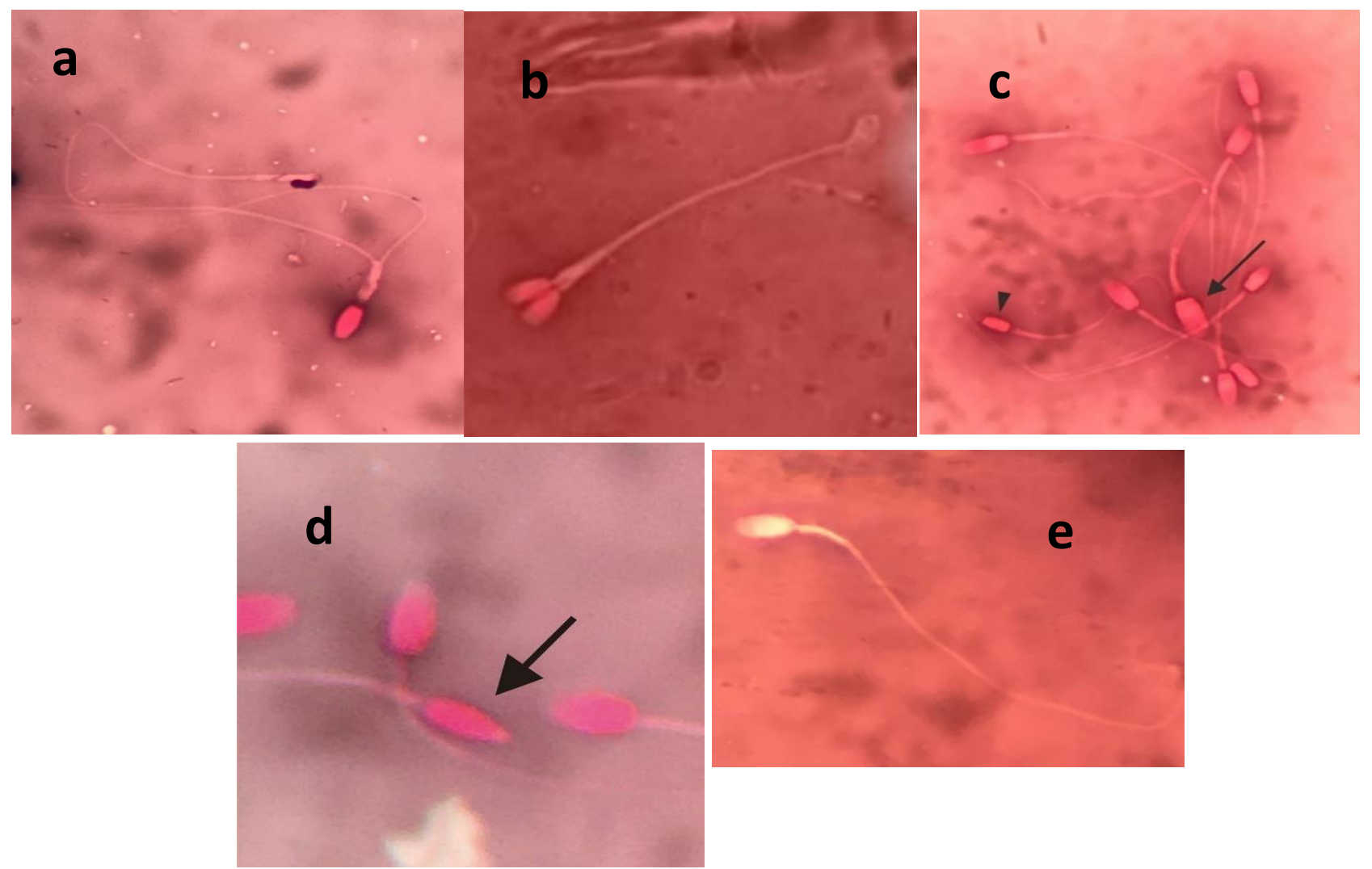

Figure 1. Hematoxylin-eosin-stained of spermatozoa from the control and the treated cats. Sperm abnormalities were found in cats after chemical sterilization with Sodium chloride. a: Double tail, b: Double head with the coiled tail, c: Macrocephalic (arrow), and microcephalic head (arrowhead), d: Elongated head, and e: normal spermatozoa
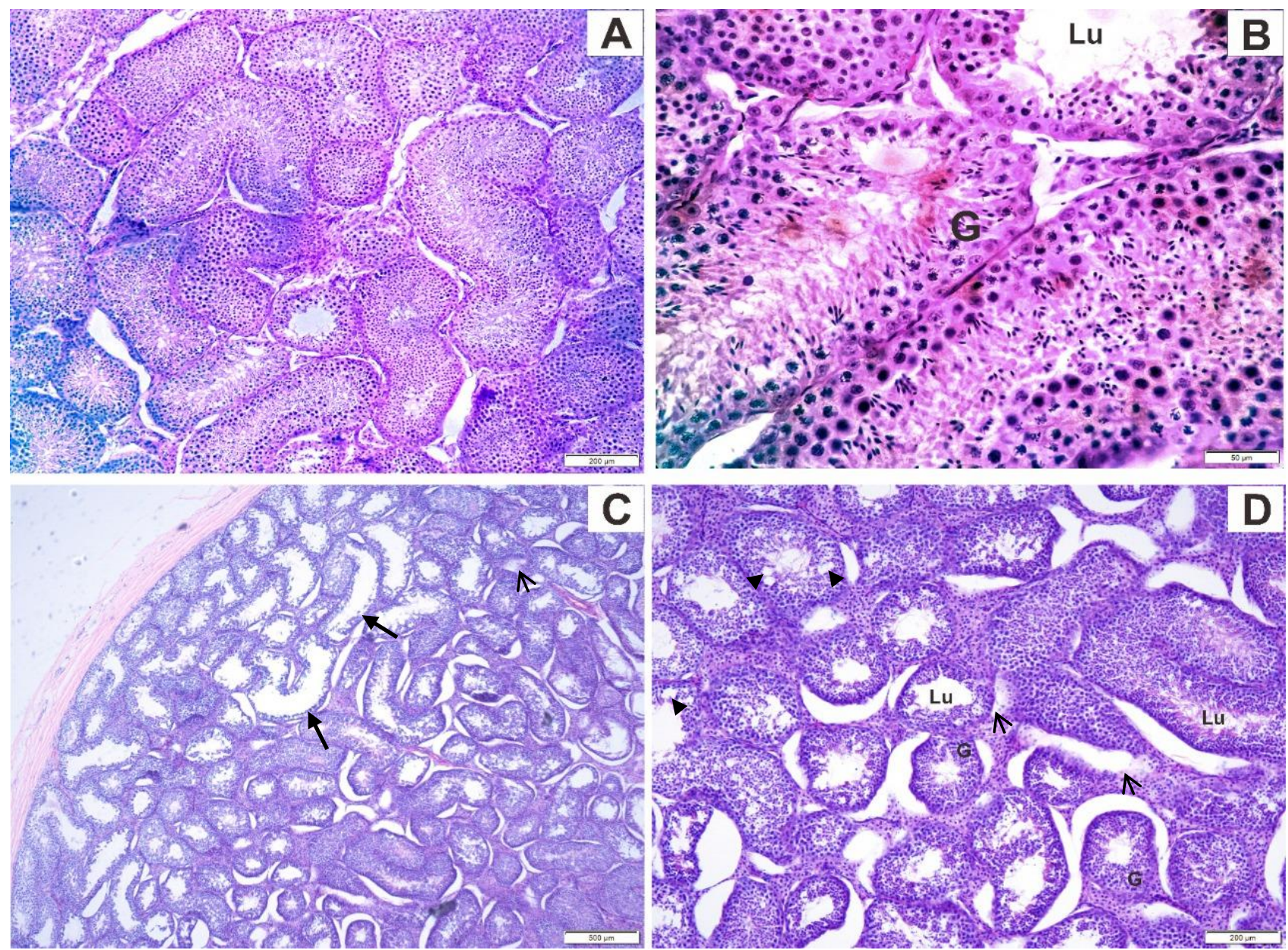

Figure 2. Histology of tests of the control and study cats at day 30 post intratesticular injection of Sodium chloride. A and B: Control groups, C and D: Group 2 (HE, original magnification x400). Degeneration of seminiferous tubules (arrow) and degeneration of Leydig cells (small arrow); vacuolation of the cytoplasm of Sertoli cells (arrowhead, c), and the lumen that is not filled with germ cells and spermatozoa (D); LU: Lumen of seminiferous tubules, G: Germs cells 


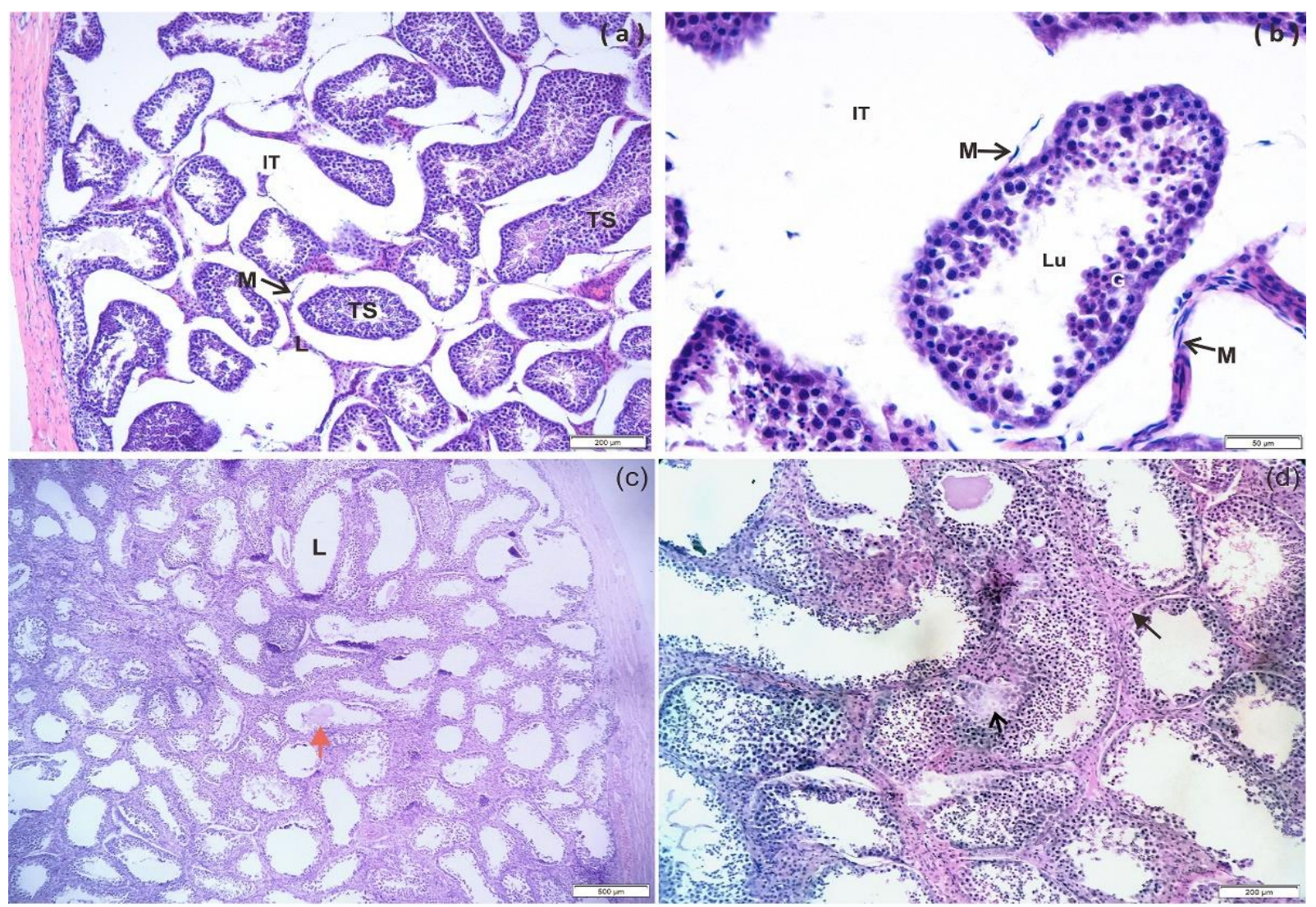

Figure 3. The testes of cats in the different experimental groups at the day 30 post intratesticular injection of Sodium chloride. Group 3 (a and $\mathbf{b}$ ) showed atrophy of the seminiferous tubules with the result of smaller size along with separate basement membrane from myoid cells, and there was degeneration of Leydig cells. Group 4 (c and d) showed a dilated lumen due to a limited amount of germ cells. TS: Tubule seminiferous, IT: Interstitial tissue, Lu: Lumen of seminiferous tubules, G: Germ cells. HE staining.

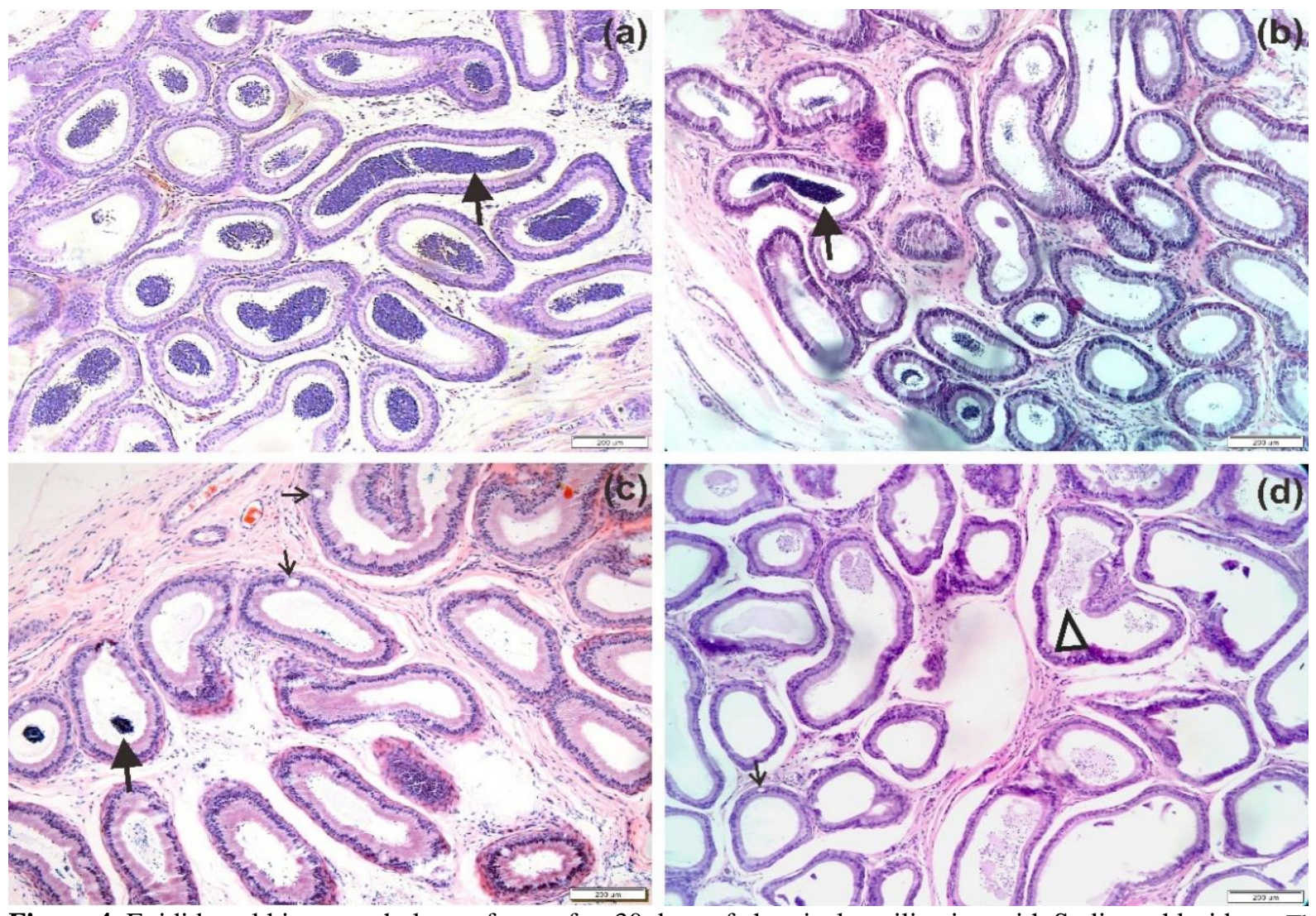

Figure 4. Epididymal histomorphology of cats after 30 days of chemical sterilization with Sodium chloride. a: The control treatment group showed that lumen of the epididymal ducts filled with spermatozoa (arrow), b: Treatment study group 2 showed that the lumen of the epididymal duct was filled with spermatozoa (arrows), but less than the control group; c: Treatment group 3 had epididymal ducts that were filled with a few spermatozoa (arrow), and there was vacuolation of the epididymal duct epitheliums (small arrow), and d: Treatment group 4 showed that the lumen of the epididymal duct was filled with small amount spermatozoa mixed with proteinase fluid (arrowhead) and vacuolated epididymal duct epithelium (small arrow). HE staining. 
Chemical castration with bilateral intratesticular injection has been studied for more than five decades with various chemicals as an alternative to contraception in pets. The present study aimed to determine the effectiveness of chemical castration in local cats using Sodium chloride on male cat fertilization which can be used to control their population without surgical extraction. The result of castration with this chemo-sterilant was expected to inhibit spermatozoa production characterized by decreased motility, viability, and increased epididymal spermatozoa abnormalities, and histomorphological changes of the testes and epididymis.

The main finding of the current research was the effectiveness of Sodium chloride for chemical castration in cats. In the present study, the administration of Sodium chloride had a significant effect on the seminiferous tubule which could be a factor for a decrease in sperm quality. This was evident by a significant decrease in sperm motility and seminiferous tubular degeneration. Spermatozoa motility is an important attribute for assessing the fertility of spermatozoa (Puja et al., 2019). Motility is the main characteristic of live spermatozoa and the simplest parameter in the assessment of semen quality, the spermatozoa tail is the part that contains all the means needed to move (da Cunha et al., 2017). Progressive motility is the ability of spermatozoa to move straight ahead in a clear direction which is important for spermatozoa movement in the female reproductive tract. Intratesticular injection of Sodium chloride in cats significantly affected the progressive motility of spermatozoa from the cauda epididymis. The results of these studies suggested that intratesticular injection of Sodium chloride could cause reproductive impairment in male cats. The mean value of sperm motility of epididymal spermatozoa in the cats with different concentrations of chemically castrated showed that motility significantly decreased, compared to the control group. Sperm motility depends on several metabolic pathways and regulatory mechanisms. Two important pathways that influence spermatozoa motility are the Calcium $(\mathrm{Ca} 2+)$ pathway and the cyclic Adenosine Monophosphate (cAMP) pathway-dependent protein kinase or Protein Kinase A (PKA, Pereira et al., 2017). Other factors besides gene defects, abnormalities in spermatozoa can also cause changes in sperm motility. There is a positive correlation between the proportion of progressive motility of spermatozoa and the morphology of spermatozoa (Robert et al., 2016). These findings indicate that Sodium chloride injection can cause severe disturbances in metabolic pathways with indicators of a marked decrease in sperm motility

The present study showed that the injection of Sodium chloride solution in the testis of a cat at the dose levels of $20 \%$ and $25 \%$ caused alterations in viability and morphology of spermatozoa. The viability and morphology of sperms were assumed to be a result of a direct effect of the hypertonic solution on testicular tissue. The direct administration of Sodium chloride into the testes causes damage to the testicular tissue, and consequently circulatory disorders. In the testes, the oxygen flow to the testes is quite low, compared to other organs, but a testis that has no disturbance can adapt to this condition so that metabolism in the seminiferous tubules runs normally (Zheng and Olive, 1997). If there is a disruption of vascularity, it can induce the death of testicular cells. This can lead to a decreased production of spermatozoa or incomplete spermatogenesis. Kwak et al. (2013) reported that Sodium chloride injection can cause severe degenerative changes and massive infiltration of immune cells in the seminiferous tubules of testes. The current study showed that sperm morphology was significantly different among the control and treatment groups. The sperm abnormalities found in the present study included doubleheader with the coiled tail, bent neck, double tail, macrocephalic with double tail, microcephalic, elongated head, and hairpin tail. The sperm abnormalities in this study were higher when compared with the normal value reported by Alves et al. (2018). Alves et al. (2018) reported that the normal value of cat sperm abnormalities was about $16.7 \pm 9.9 \%$.

The current study showed that the administration of Sodium solution in the testis of cats could cause atrophy of seminiferous tubular. Similar results were observed in cats treated with Sodium chloride solution which revealed atrophy of seminiferous tubule (Ijaz et al., 2019). Kwak and Lee (2013) found severe degenerative changes in testicular seminiferous tubules and massive infiltration of immune cells in the hypertonic saline group. Testicular atrophy is the most common lesion found in testicular toxicity. Histologically, the indicator of testicular cell atrophy is the partial or complete loss of mature spermatids from the tubular lumen. As the severity of the atrophy increases, deeper layers of cells disappear progressively. This was indicated by the presence of only a few spermatogonia cells and Sertoli cells. Other cytological features included germ cell vacuolation and the presence of multinucleate giant cells. The progressive loss of germ cells caused the seminiferous tubules to shrink, which resulted in the thickening of the fibrous walls and until it reaches the final stage of total sclerosis where there are only interstitial cell residues (Woldemeskel, 2017). The vacuolation of seminiferous tubular germ cells occurs due to degenerative changes or physical loss of germ cells (Creasy et al., 2012), which can be an early morphological indicator of Sertoli cell disorders (Creasy, 2001), and fluid balance disorders from Sertoli cells (Hild et al., 2001).

Histopathological studies on the epididymis of cats treated with Sodium chloride solution showed that there was a significant depletion of spermatozoa in the lumen of the epididymis. The depletion of the spermatozoa may be caused by testicular degeneration, testicular parenchymal atrophy, seminiferous epithelial degeneration, and impaired spermatogenesis. Other researchers have reported similar results in impaired spermatogenesis and a decrease in sperm 
parameters in dogs treated with Sodium chloride solution (Canpolat et al., 2016). The epididymal sperm concentration reflected a decrease in spermatogenesis in the testes (Oguejiofor et al., 2020). In the treatment groups, vacuolation of ductus epithelium of epididymis was detected. The finding of the present study showed that an intratesticular injection of Sodium chloride solution has a proper impact on the epithelium of epididymis.

\section{CONCLUSION}

The injection of 20-25\% Sodium chloride has the potential to be an alternative to non-surgical sterilization and is easily performed in male cats. Sodium chloride is minimally invasive, cost-saving, and efficacious as a chemosterilant. In an effort to improve the safety and absence of fertility recovery, additional studies must be performed for a longer observation period.

\section{DECLARATION}

\section{Competing interests}

The author declared that there is no conflict of interest.

\section{Acknowledgments}

The authors would like to thank the cat community in Denpasar for the animals used in this research.

\section{Authors' contribution}

All of the authors have participated equally in this study, read, and approved the manuscript

\section{Ethical consideration}

Ethical issues (including plagiarism, consent to publish, misconduct, data fabrication and/or falsification, double publication and/or submission, and redundancy) have been checked by the authors

\section{REFERENCES}

Abshenas J, Molaei MM, Derakhshnfar A, and Ghalekhani N (2013). Chemical sterilization by intratesticular injection of Eugenia Caryophyllata essential oil in dog: A histopathological study. Iranian Journal of Veterinary Surgery, 8(2): 9-16. Available at: http://www.ivsajournals.com/article 4381 011c6d55d467cf03dcf249fda73f3f5b.pdf

Alves IP, Cancelli CHB, Grassi TLM, Oliveira PRH, Franciscato DA, Carreira JT, and De Koivisto BK (2018). Evaluation of sperm head dimensions and chromatin integrity of epididymal sperm from domestic cats using the toluidine blue technique. Animal Reproduction Science, 197: 33-39. DOI: https://www.doi.org/10.1016/j.anireprosci.2018.08.001

Belhan S, and Gülyüz F (2018). Collection of semen from van cats using electroejaculation and freezing of semen. International Journal of Veterinary Science, 7(1): 7-11. Available at: http://www.ijvets.com/pdf-files/Volume-7-no-1-2018/7-11.pdf

Canpolat I, Karabulut E, and Eroksuz Y (2016). Chemical castration of adult and non-adult male dogs with Sodium chloride solution. IOSR Journal of Agriculture and Veterinary Science, 9(12): 9-11. DOI: https://www.doi.org/10.9790/2380-0912010911

Cavalieri J (2017). Chemical sterilization of animals: A review of the use of zinc-and $\mathrm{CaCl} 2$ based solutions in male and female animals and factors likely to improve responses to treatment. Animal Reproduction Science, 181: 1-8. DOI: https://www.doi.org/10.1016/j.anireprosci.2017.03.010

Creasy DM (2001). Pathogenesis of male reproductive toxicity. Toxicologic Pathology, 29(1): 64-76. DOI: https://www.doi.org/10.1080/019262301301418865

Creasy D, Bube A, Rijk ED, Kandori H, Kuwahara M, Masson R, Nolte T, Reams R, Regan K, Rehm S et al. (2012). Proliferative and nonproliferative lesions of the rats and mouse male reproductive system. Toxicologic Pathology, 40: 40-121. DOI: https://www.doi.org/10.1177/0192623312454337

da Cunha ICN, De Ascençao RA, Quirino CR, and Gimenes ALL (2017). The efficacy of in vitro sperm tests in predicting pregnancy success after artificial insemination in the bitch. Andrology (Los Angel), 6: 190. DOI: https://www.doi.org/10.4172/2167$\underline{0250.1000190}$

de Sousa Barbosa B, Silva HVR, de Almeida Tabosa BE, Nunes TGP, de Magalhães FF, and da Silva LDM (2019). Morphological and morphometric characterization of domestic cat epididymal sperm. Reproduction in Domestic Animals, 54(12): 1630-1636. DOI: https://www.doi.org/10.1111/rda.13572

Emir L, Dadah M, Sunay M, Erol D, Caydere M, and Ustun H (2008). Chemical castration with intratesticular injection of $20 \%$ hypertonic saline: A minimally innvasive method. Urologic Oncology, 26: 392-396. DOI: https://www.doi.org/10.1016/j.urolonc.2007.05.013

Flockhart DTT, and Coe JB (2018). Multistate matrix population model to assess the contributions and impacts on population abundance of domestic cats in urban areas including owned cats, unowned cats, and cats in shelters. PLoS One, 13(2): e0192139. DOI: https://www.doi.org/10.1371/journal.pone.0192139 
Hassan A, and Fromsa A (2017). Review on chemical sterilization of male dogs. International Journal of Advanced Research, 5(11): 758-770. DOI: https://www.doi.org/10.21474/IJAR01/5828

Heath D (1995). An introduction to experimental design and statistics for biology. 2rd Edition. UCL Press, London. pp. 282-296. DOI: https://www.doi.org/10.1201/b12546

Hild SA, Reel JR, Larener JM, and Blye RP (2001). Disruption of spermatogenesis and Sertoli cell structure and function by the Indenopyridine CDB-4022 in rats. Biology of Reproduction, 65: 1771-1779. DOI: https://www.doi.org/10.1095/biolreprod65.6.1771

Ibrahim A, Ali MM, Abou-Khalil NS, and Ali MF (2016). Evaluation of chemical castration with calcium chloride versus surgical castration in donkeys: Testosterone as an endpoint marker. BMC Veterinary Research, 12: Article number 46. DOI https://www.doi.org/10.1186/s12917-016-0670-3

Ijaz M, Rizwan AA, Asad M, Anas SQ, Faiza H, Tahir M, Zia MD, Khizar H, and Rubi T (2019). Comparative evaluation of single, bilateral intra-testicular injection of hypertonic saline solution and Calcium chloride as chemical sterilizing agents in male cats. Biomedical Journal of Scientific and Technical Research, 21(3): 15858-15864. DOI: https://www.doi.org/10.26717/BJSTR.2019.21.003598

Jana K, and Samanta PK (2011). Clinical evaluation of non-surgical sterilization of male cats with single intra-testicular injection of Calcium chloride. BMC Veterinary Research, 39(7): 1-15. DOI: https://www.doi.org/10.1186/1746-6148-7-39

Kennedy BPA, Cumming B, and Brown WY (2020). Global strategies for population management of domestic cats (Felis catus): A systematic review to inform best practice management for remote indigenous communities in Australia. Animals, 10(4): 663. DOI: https://www.doi.org/10.3390/ani10040663

Kwak BK, Lee C, and Lee S (2010). Histological changes in rat testis by injection of hypertonic saline. Development Reproduction, 14(4): 281-286. Available at: http://www.koreascience.or.kr/article/JAKO201015537949137.pdf

Kwak BK, and Lee SH (2013). Intratesticular injection of hypertonic saline: Non-invasive alternative method for animal castration model. Development Reproduction, 7(4): 435-440. DOI: https://www.doi.org/10.12717/DR.2013.17.4.435

Leoci R, Audi G, Silvestre F, Lissner EA, Marino F, and Lacalandra GM (2014). A dose-finding, long-term study on the use of calcium chloride in saline solution as a method of nonsurgical sterilization in dogs: Evaluation of the most effective concentration with the lowest risk. Veterinaria Scandinavica, 56: 1-8. DOI: https://www.doi.org/10.1186/s13028-014-0063-1

Macente BI, Gutierrez RR, Apparício M, De Carvalho Balieiro C, Mansano CFM, Pereira MM, Borges-Silva JC, and Pires-Buttler EA (2018). Cat epididymal semen cryopreserved with and without Vitamin E: Effect on sperm parameters and lipid peroxidation, Animal. Reproduction, 15(4): 1193-1198. DOI: https://www.doi.org/10.21451/1984-3143-AR2018-0001

Mitsui K, Sato S, and Kakuma Y (2020). Effects of the community cats program on population control, migration and welfare status of free-roaming cats in Tokyo, Japan. Animals, 10: 461. DOI: https://www.doi.org/10.3390/ani10030461

Oguejiofor CF, Kenneth OA, and Nnaemeka KO (2020). Unilateral testicular degeneration in dogs: Effects on spermatozoal characteristics, testis, and cauda epididymis. Ethiopian Veterinary Journal, 24(2): 149-154. DOI: https://www.doi.org/10.4314/evj.v24i2.9

Pereira R, Sá R, Barros A, and Sousa M (2017). Major regulatory mechanisms involved in sperm motility. Asian Journal of Andrology, 19: 5-14. DOI: https://www.doi.org/10.4103/1008-682X.167716

Pintus E, Kadlec M, Karlasová B, Popelka M, and Ros-Santaella JL (2021). Spermatogenic activity and sperm traits in post-pubertal and adult tomcats (Felis catus): Implication of intra-male variation in sperm size. Cells, 10: 624. DOI: https://www.doi.org/10.3390/cells 10030624

Puja IK, Sawitri NM, Maharani N, Heryani LGSS, Dharmayudha AAGO, and Gunawan IWNF (2019). Preservation of semen from Kintamani Bali dogs by freezing method. Journal of Advanced Veterinary and Animal Research, 6(2): 158-162. DOI: https://www.doi.org/10.5455/javar.2019.f326

Rafatmah D, Asghar M, and Davoud E (2019). Chemical sterilization with intratesticular administration of zinc gluconate in adult dogs: A preliminary report. Basic Clinical Andrology, 29(12): 1-9. DOI: https://www.doi.org/10.1186/s12610-019-0092-8

Robert MA, Jayaprakash G, Pawshe M, Tamilmani T, and Sathiyabarathi M (2016). Collection and evaluation of canine semen-a review. International Journal of Science, Environment and Technology, 5(3): 1586-1595. Available at: https://www.ijset.net/journal/1040.pdf

Toyonaga M, and Tsutsui T (2012). The quality of cryopreserved sperm collected from feline caudal epididymides using seminal plasma. Journal of Veterinary Medical Science, 74(10): 1349-1353. DOI: https://www.doi.org/10.1292/jvms.11-0175

Woldemeskel M (2017). Toxicology pathology of reproductive system. Reproductive and Developmental Toxicology, 64(12): 12101233. DOI: https://www.doi.org/10.1016/B978-0-12-804239-7.00064-0

Zheng H, and Olive PL (1997). Influence of oxygen on radiation-induced DNA damage in testicular cells of C3H mice. International Journal of Radiation Biology, 71: 275-282. DOI: https://www.doi.org/10.1080/095530097144157 